\title{
Impact of COVID-19 Crisis on Exam Anxiety Levels among Bachelor Level University Students
}

\author{
Isra Alsaady \\ Hattan Gattan \\ Ayat Zawawi \\ Maimonah Alghanmi \\ Haytham Zakai \\ Faculty of Applied Medical Sciences, \\ Department of Medical Laboratory Sciences, \\ King Abdulaziz University, Jeddah 21589, Saudi Arabia
}

DOI: https://doi.org/10.36941/mjss-2020-0052

Abstract

COVID-19 crisis had a huge impact on education and academics. Besides, it might have generated public fear and worry. All these factors might affect students' performance and wellbeing and might increase stress levels especially during exams. Therefore, this study will investigate the impact of COVID-19 crisis on student's exam anxiety and its relationship with other factors. A cross-sectional study was conducted by distributing exam anxiety survey electronically to Saudi universities bachelor students, two hundred and seventy-two students have responded to the survey. The results have shown that both female and male student have high anxiety levels. And no significant correlation was found between any demographic data and anxiety level, except the gender, as female students have a higher anxiety level than male students. In conclusion, COVID-19 might had generated a high exam anxiety level, especially in female students. Therefore, facilitating initiatives might be considered to improve students' performance during this crisis.

Keywords: Exam anxiety, education, COVID-19, stress, students' performance

\section{Introduction}

Students and academics have been through big changes in education due to COVID-19 crisis. As a result, some students start to worry about these changes in education styles and their impact on their academic achievements. Anxiety is a public phenomenon that constitutes a universal cause of inadequate performance among people worldwide and plays an important role in their life. Moreover, a normal level of anxiety is useful in keeping up people hardworking and having the responsibility for their obligations (Kahan, 2008) (Donnelly, 2009). One of these anxieties is exam anxiety.

Assessing the performance of the students is a complex task. Therefore, instructors need to use different assessment methods, including exams to assess the students' performance fairly and objectively. Subsequently, many important academic decisions will be made based on exams' results. 
Hence, it is not surprising that exam anxiety has been a major problem for many students all over the world (Anisa \& Miranda, 2011). Exam anxiety is defined as a set of phenomenological, physiological, and behavioural response that result upon overthinking of the negative consequences of failing an exam or any other academic evaluations (Zeidner, 1998) Exam anxiety varies from one individual to another as it depends on different variables, such as lifestyle issues, lack of required information, studying style, and psychological factors (Frischenschlager, Haidinger, \& Mitterauer, 2005). The most common lifestyle issues related to exam anxiety are tiredness, inadequate physical activity, malnutrition and inefficient time management (Parkerson, Broadhead, \& Tse, 1990)(Acharya, 2003). In addition, Lack of strategic studying such as ineffective studying style and inefficient studying of course material are the major factors leading to exam anxiety(Sansgiry \& Sail, 2006). Psychological factors which lead to exam anxiety include overthinking about exams, exam outcomes, and feelings of lost control over exam situation (Alexander \& Haldane, 1979)(Miller McC \& Surtees, 1991). As a result, some individuals will have no problem and will be calm when doing an exam, while others will overthink about the exam as dangerous or threatening experience and could suffer from more intense levels of anxiety (Spielberger \& Vagg, 1995). Furthermore, different studies showed that females have a higher level of exam anxiety than males(Hembree, 1990) (Bandalos, Yates, \& Thorndike-Christ, 1995) However, less is known about whether or not gender differences might have an impact on their academic achievements. A meta-analysis study by Hembree, 1988 showed that a high level of exam anxiety in females might not lead to poor performance (Hembree, 1988). Another study revealed the same result that females might have higher exam anxiety than males; however, exam anxiety might not have an impact on academic performance (Núñez-Peña, Suárez-Pellicioni, \& Bono, 2016).

Due to COVID-19 crisis, education was shifted into emergency remote learning, and virtual classes were given through different educational platforms such as Blackboard, Zoom, and Google classroom. Besides, all assignments were handed out and submitted electronically to keep on evaluating students through different evaluation strategies. At the end of the semester, an online exam was assigned through blackboard as the final evaluation of the students' performance. this study aims to measure exam anxiety upon an undergraduate student during COVID-19 crisis.

\section{Method}

\section{$2.1 \quad$ Research method}

Exam Anxiety Questionnaire as described by (Sarason, 1973) was used to assess exam anxiety in this study. A cross-section study was conducted on bachelor Saudi university students from $14^{\text {th }}$ to $24^{\text {th }}$ of April 2020. After obtaining ethical approval from the ethical committee of faculty of applied medical science at King Abdulaziz University. Exam Anxiety Questionnaire can be described as 38 items that use 4-points, Likert-type instrument ranging from strongly agree to strongly disagree. Each student read each situation and responds with the appropriate scale to indicate how they react to each one. Questionnaire spread out electronically to undergraduate students by email, blackboard or social media. Students' consent was obtained at the beginning of the questionnaire. The questions were divided into two parts, the first part includes some general questions about the age, gender, and year of study and the second part was all about anxiety scenarios.

\subsection{Statistical analysis}

Data were statistically analysed using SPSS version 22. Simple descriptive statistics were used to define the characteristics of demographic data in the form of students' number and percentages for each demographic variable. To investigate the relationship between categorical variables, this study used the student T-test. Lastly, a conventional P-value <0.05 was the criteria to reject the null hypothesis. 


\section{Results}

The exam anxiety questionnaire was distributed electronically among bachelor university students as described above. Two hundred and seventy-two participants answered the questionnaire. More females participated in the study (62.1\%). Participants aged between $18-25^{+}$with a mean age of 21.2 years (SD-1.65). Participants were at different years of study ranging from first to the sixth year as shown in table 1. Participants studied at different faculties as shown in table 2 with the majority $(47.4 \%)$ from the faculty of applied medical sciences. Most of the participants were single (93.4\%) as shown in Table 3 .

Calculation of the exam anxiety level revealed that both male and female students have high levels of anxiety. The mean values of exam anxiety were 95.3 and 99.6 for male and female students respectively ( $\mathrm{SD}=\mathbf{2 4 . 0}$ and 22.5 respectively). Comparison of means using t-test revealed a statistically significant difference $(p<0.05)$ between the mean anxiety score and the sex of participants. Female students had higher levels of exam anxiety compared to male students. There are no statistically significant differences between mean exam anxiety scores and other demographic data.

Table 1: Participant's study level

\begin{tabular}{|l|c|c|}
\hline Year & Number of students & Percentage (\%) \\
\hline First-year & 27 & 9.9 \\
\hline Second-year & 92 & 33.8 \\
\hline Third-year & 75 & 27.6 \\
\hline Fourth-year & 63 & 23.2 \\
\hline Fifth-year & 6 & 2.2 \\
\hline Sixth year & 9 & 3.3 \\
\hline
\end{tabular}

Table 2: Participant's faculty

\begin{tabular}{|l|c|c|}
\hline Faculty & Number of students & Percentage (\%) \\
\hline Economics \& Administration & 43 & 15.8 \\
\hline Arts and Humanities & 8 & 2.9 \\
\hline Science & 56 & 20.6 \\
\hline Engineering & 6 & 2.2 \\
\hline Medicine & 2 & .7 \\
\hline Applied Medical Sciences & 129 & 47.4 \\
\hline Law & 11 & 4.0 \\
\hline Applied Studies & 1 & .4 \\
\hline Dentistry & 4 & 1.5 \\
\hline Tourism & 1 & .4 \\
\hline Communication and Media & 3 & 1.1 \\
\hline Computing \& IT & 6 & 2.2 \\
\hline Medical rehabilitation sciences & 2 & .7 \\
\hline
\end{tabular}

Table 3: Participant's marital status

\begin{tabular}{|l|c|c|}
\hline Marital status & Number of students & Percentage (\%) \\
\hline Single & 254 & 93.4 \\
\hline Married & 11 & 4.0 \\
\hline Divorced & 7 & 2.6 \\
\hline Widowed & 0 & 0 \\
\hline
\end{tabular}




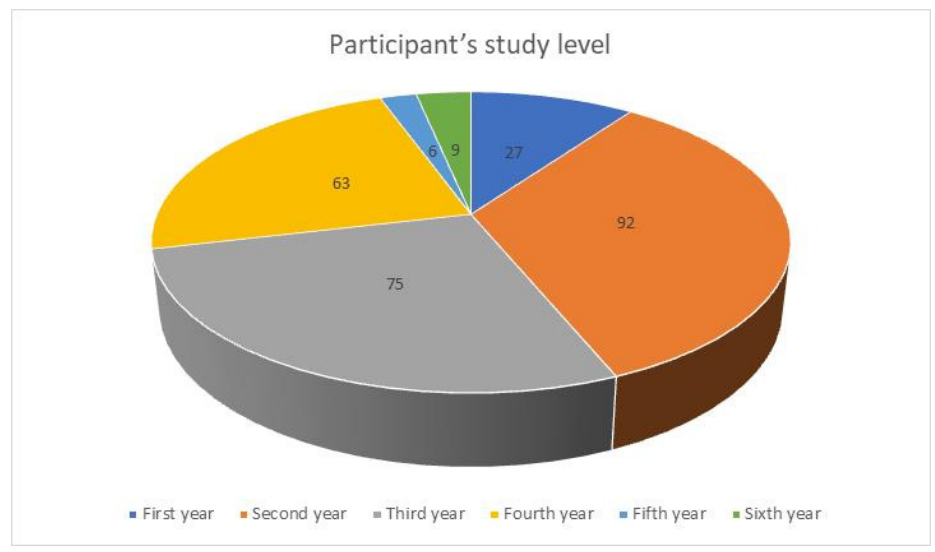

Figure 1: Participant's study level.

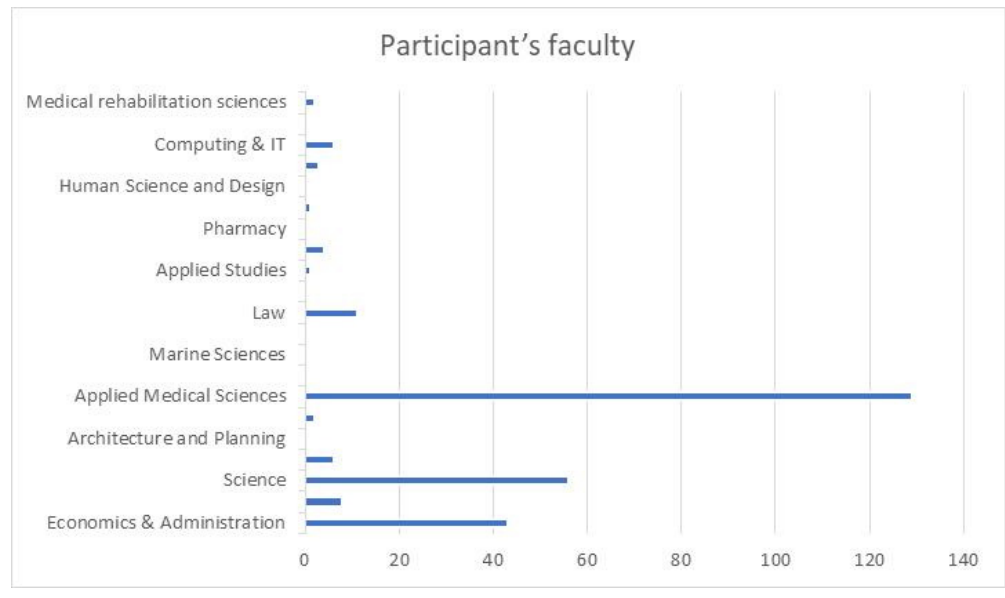

Figure 2: Participant's faculty

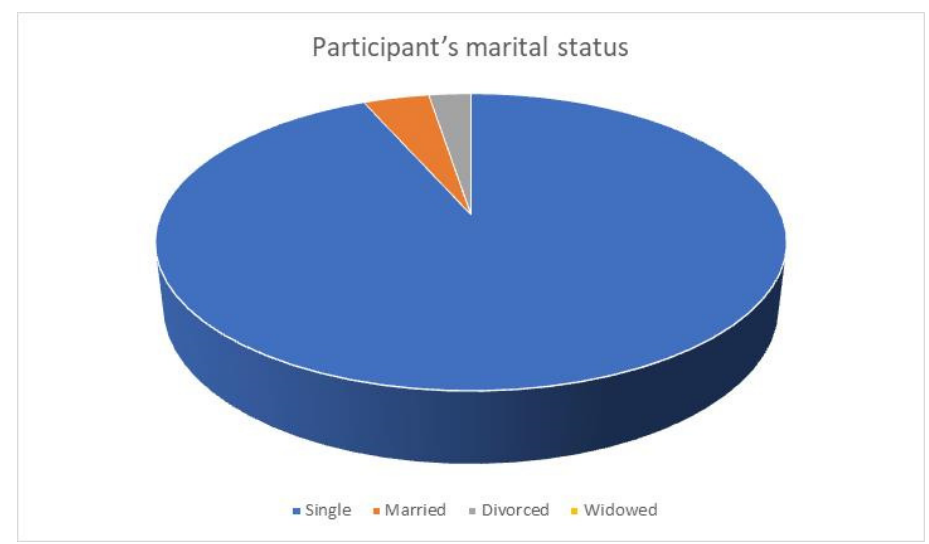

Figure 3: Participant's marital status 


\section{Discussion}

Public health emergencies might influence the university student's psychological health. University students might experience anxiety, fear, and worry. To observe the effect of Covid-19 on exam anxiety levels among bachelor level university students. Exam anxiety survey was distributed electronically among university students. Results have shown that both male and female students have high levels of exam anxiety and female students have higher levels of exam anxiety than male students.

Students' high exam anxiety levels during COVID-19 might be related to the effect of the pandemic on their studies and future employments (Cornine, 2020). A study conducted on Chinese students has revealed that the COVID-19-related stressors are financial stressors, effects on daily-life, and academic suspensions, these stressors were positively associated with anxiety symptoms (Cao et al., 2020).

Several factors might generate community anxiety including people fear of getting infected by the virus, the uncertainty and unpredictable future of this pandemic has been worsened by myths and misinformation. These worries are often triggered by incorrect news reports and the community's misunderstanding of health instructions, leading to increase community worry levels. Adding up travel bans and instructions to quarantine travellers could lead to creating public anxiety while trying to control the pandemic, leading to complications that exceed the consequences of COVID-19 pandemic itself (Bao, Sun, Meng, Shi, \& Lu, 2020). Also, lockdown regulations might trigger anxiety. Xiao 2020 (Xiao, 2020) suggested that the lack of interpersonal communication might increase the possibility of occurrence and deterioration of depression and anxiety.

T-test analysis suggests that exam anxiety is related to gender, the anxiety level is higher among female students than male students. Our finding is in alignment with a previous study investigated exam anxiety among medical students at Taibah University. The study reported that female students had high anxiety levels as compared with males, and suggested that the high anxiety levels are due to extensive study load, long exam duration, tiredness and negative ideas (Khoshhal, Khairy, Guraya, \& Guraya, 2017). A similar result was reported in a study conducted in Jizan on undergraduate students to investigate general anxiety level (Hakami, 2018) consistent with the findings of preceding studies (Rosal et al., 1997) (Shaikh et al., 2004). Though, other studies showed that the male has a higher anxiety level than female (Khan, Mahmood, Badshah, Ali, \& Jamal, 20o6) or no gender variances (Niemi \& Vainiomäki, 2006).

However, as mentioned earlier the correlation between the exam anxiety and performance is debatable. As many studies reported a higher anxiety level in female, yet females performance is higher than male performance (Chapell et al., 2005).

Demographic data were obtained to investigate the students' group that needs more support and intervention. However, the results have shown no statistically significant differences between mean exam anxiety scores and demographic data. Therefore, perhaps educators can apply psychometrically sound tools to decide the need for exam anxiety intervention with specific examing conditions instead of directly aiming demographic group (N. von der Embse, Jester, Roy, \& Post, 2018).

Finally, as the educators' role is to facilitate the examing environment to the student not debilitating it (N. P. von der Embse, Mata, Segool, \& Scott, 2014), the Ministry of Education decisions to reduce the final exam total marks was a right decision, taking in consideration the high exam anxiety during COVID-19 crisis.

\section{Conclusion}

This study has clearly shown that exam anxiety highly prevalent among bachelor students in Saudi Arabia during COVID-19 crisis and Female students showed a higher level of exam anxiety. Findings from this study necessitate that implementing a strategy for facilitating exam environment is highly recommended to minimize the impact of COVID-19 crisis on student's performance and psychological well -being. 


\section{Reference}

Acharya, S. (2003). Factors affecting stress among Indian dental students. Journal of Dental Education.

Alexander, D. A., \& Haldane, J. D. (1979). Medical education: a student perspective. Medical Education.

Anisa, T., \& Miranda, S. (2011). How Does Exam Anxiety Affect the Performance of University Students? Mediterranean Journal of Social Sciences.

Bandalos, D. L., Yates, K., \& Thorndike-Christ, T. (1995). Effects of Math Self-Concept, Perceived Self-Efficacy, and Attributions for Failure and Success on Test Anxiety. Journal of Educational Psychology. https://doi.org/10.1037/oo22-0663.87.4.611

Bao, Y., Sun, Y., Meng, S., Shi, J., \& Lu, L. (2020). 2019-nCoV epidemic: address mental health care to empower society. The Lancet. https://doi.org/10.1016/So140-6736(20)30309-3

Cao, W., Fang, Z., Hou, G., Han, M., Xu, X., Dong, J., \& Zheng, J. (2020). The psychological impact of the COVID19 epidemic on college students in China. Psychiatry Research. https://doi.org/10.1016/j.psychres.2020.112934

Chapell, M. S., Benjamin Blanding, Z., Takahashi, M., Silverstein, M. E., Newman, B., Gubi, A., \& McCann, N. (2005). Test anxiety and academic performance in undergraduate and graduate students. Journal of Educational Psychology. https://doi.org/10.1037/oo22-0663.97.2.268

Cornine, A. (2020). Reducing Nursing Student Anxiety in the Clinical Setting. Nursing Education Perspectives. https://doi.org/10.1097/o1.nep.ooooooooooooo633

Donnelly, R. C. (2009). Embedding interaction within a blend of learner centric pedagogy and technology. World Journal on Educational Technology.

Frischenschlager, O., Haidinger, G., \& Mitterauer, L. (2005). Factors associated with academic success at Vienna Medical School: Prospective survey. Croatian Medical Journal.

Hakami, R. (2018). Prevalence of psychological distress among undergraduate students at Jazan University: A cross-sectional study. Saudi Journal of Medicine and Medical Sciences. https://doi.org/10.4103/sjmms.sjmms_73_17

Hembree, R. (1988). Correlates, Causes, Effects, and Treatment of Test Anxiety. Review of Educational Research. https://doi.org/10.3102/00346543058001047

Hembree, R. (1990). The Nature, Effects, and Relief of Mathematics Anxiety. Journal for Research in Mathematics Education. https://doi.org/10.2307/749455

Kahan, D. M. (2008). Cultural cognition as a conception of the cultural theory of risk. HANDBOOK OF RISK THEORY, S. Roeser, Ed., Forthcoming, 8-20.

Khan, M. S., Mahmood, S., Badshah, A., Ali, S. U., \& Jamal, Y. (2006). Prevalence of depression, anxiety and their associated factors among medical students in Karachi, Pakistan. Journal of the Pakistan Medical Association.

Khoshhal, K. I., Khairy, G. A., Guraya, S. Y., \& Guraya, S. S. (2017). Exam anxiety in the undergraduate medical students of Taibah University. Medical Teacher. https://doi.org/10.1080/0142159X.2016.1254749

Miller McC, P., \& Surtees, P. G. (1991). Psychological symptoms and their course in first-year medical students as assessed by the Interval General Health Questionnaire (I-GHQ). British Journal of Psychiatry. https://doi.org/10.1192/bjp.159.2.199

Niemi, P. M., \& Vainiomäki, P. T. (2006). Medical students' distress - Quality, continuity and gender differences during a six-year medical programme. Medical Teacher. https://doi.org/10.1080/01421590600607088

Núñez-Peña, M. I., Suárez-Pellicioni, M., \& Bono, R. (2016). Gender Differences in Test Anxiety and Their Impact on Higher Education Students' Academic Achievement. Procedia - Social and Behavioral Sciences. https://doi.org/10.1016/j.sbspro.2016.07.023

Parkerson, G. R., Broadhead, W. E., \& Tse, C. J. (1990). The health status and life satisfaction of first-year medical students. Academic Medicine. https://doi.org/10.1097/000o1888-199009000-0ooo9

Rosal, M. C., Ockene, I. S., Ockene, J. K., Barrett, S. V., Ma, Y., \& Hebert, J. R. (1997). A longitudinal study of students' depression at one medical school. Academic Medicine. https://doi.org/10.1097/oooo1888$199706000-00022$

Sansgiry, S. S., \& Sail, K. (2006). Effect of students' perceptions of course load on test anxiety. American Journal of Pharmaceutical Education. https://doi.org/10.5688/aj700226

Sarason, I. G. (1973). Test anxiety and cognitive modeling. Journal of Personality and Social Psychology. https://doi.org/10.1037/hoo35476

Shaikh, B. T., Kahloon, A., Kazmi, M., Khalid, H., Nawaz, K., Khan, N. A., \& Khan, S. (2004). Students, stress and coping strategies: A case of Pakistani Medical School. Education for Health. https://doi.org/10.108o/13576280400002585

Spielberger, C., \& Vagg, P. (1995). Test anxiety: A transactional process model. In Test anxiety Theory assessment and treatment. 
von der Embse, N., Jester, D., Roy, D., \& Post, J. (2018). Test anxiety effects, predictors, and correlates: A 30-year meta-analytic review. Journal of Affective Disorders. https://doi.org/10.1016/j.jad.2017.11.048

von der Embse, N. P., Mata, A. D., Segool, N., \& Scott, E. C. (2014). Latent Profile Analyses of Test Anxiety: A Pilot Study. Journal of Psychoeducational Assessment. https://doi.org/10.1177/0734282913504541

Xiao, C. (2020). A novel approach of consultation on 2019 novel coronavirus (COVID-19)-related psychological and mental problems: Structured letter therapy. Psychiatry Investigation. https://doi.org/10.30773/pi.2020.0047

Zeidner, M. (1998). Test anxiety: The state of the art. Springer Science \& Business Media. 